\title{
Minimally invasive surgical approaches to thoracic sympathectomy for hyperhidrosis
}

\author{
Farid Gharagozloo, Mark Meyer \\ Center for Advanced Thoracic Surgery, Global Robotics Institute, Advent Health Celebration, University of Central Florida, \\ Celebration, FL 34786, USA.
}

Correspondence to: Dr. Farid Gharagozloo, Center for Advanced Thoracic Surgery, Global Robotics Institute, Advent Health Celebration, University of Central Florida, 400 Celebration Place, Celebration, FL 34786, USA.

E-mail: farid.gharagozloo.md@adventhealth.com

How to cite this article: Gharagozloo F, Meyer M. Minimally invasive surgical approaches to thoracic sympathectomy for hyperhidrosis. Mini-invasive Surg 2020;4:48. http://dx.doi.org/10.20517/2574-1225.2020.35

Received: 13 Apr 2020 First Decision: 13 May 2020 Revised: 18 May 2020 Accepted: 1 Jun 2020 Published: 7 Aug 2020

Academic Editor: Noriyoshi Sawabata Copy Editor: Cai-Hong Wang Production Editor: Jing Yu

\begin{abstract}
Thoracic sympathectomy is used for the palliation of hyperhidrosis. However, significant controversies surround the optimal surgical approach and the extent of sympathectomy. The determinants of success in the surgical palliation of hyperhidrosis are the postoperative rate of anhidrosis, recurrence of symptoms, and rate of compensatory hyperhidrosis. This paper attempts to shed light on the controversies by examining the historic background, clearly defining the anatomic considerations, and outlining the various surgical approaches culminating with robotic selective dorsal thoracic sympathectomy.
\end{abstract}

Keywords: Sympathectomy, hyperhidrosis, robotic, minimally invasive, thoracoscopic, selective sympathectomy

\section{INTRODUCTION}

Surgery on the sympathetic nervous system (SNS) is characterized by the evolution of indications and techniques that have correlated with the evolution and understanding of the physiology and anatomy of this complex part of the nervous system.

By the end of the 18th century, the anatomy of the sympathetic system was well described ${ }^{[1]}$. However, it was over a century later that a clearer understanding of the SNS as part of the autonomic nervous system was achieved $^{[2]}$. In 1852, Bernard ${ }^{[3]}$ discovered that division of the cervical sympathetic trunk resulted in an

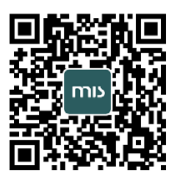




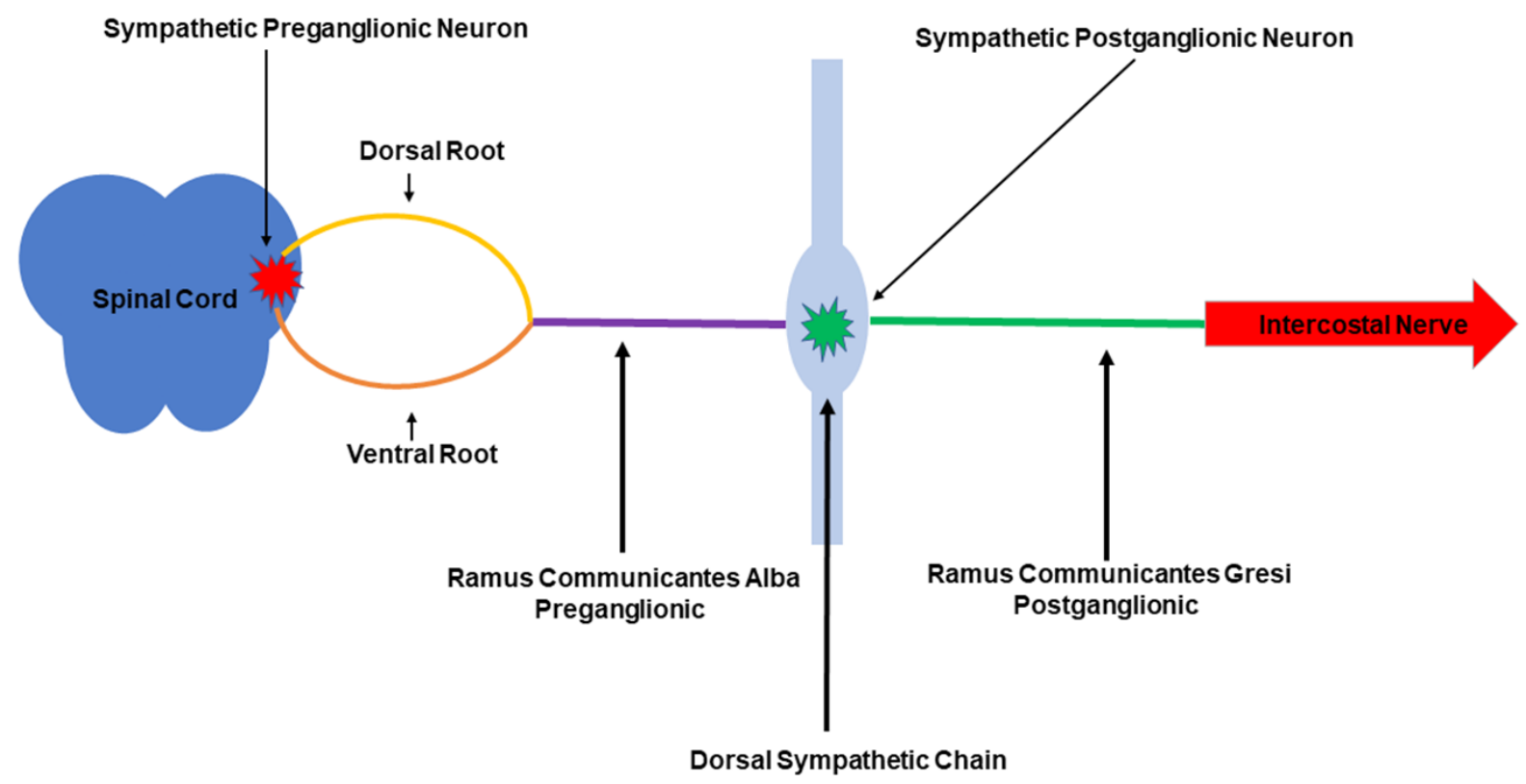

Figure 1. Sympathetic chain. Schematic representation shows the location of the first neuron in the spinal cord. Axons from the first neuron (preganglionic) travel within the dorsal and ventral roots and form the preganglionic sympathetic fibers or rami communicantes albi (white rami). Rami communicantes albi synapse with the second neuron within the sympathetic chain and the postganglionic fibers or ramus communicantes grisei (grey rami) travel with the intercostal nerves

increase in the temperature of the ipsolateral side of the face. On the other hand, during the same period, Brown-Sequard $^{[4]}$ noted that stimulation of the sympathetic nerves resulted in vasoconstriction. The first surgical sympathectomy was performed by Alexander ${ }^{[5]}$ in 1889 for the treatment of epilepsy. Jonnesco ${ }^{[6]}$ (1896) and Jaboulay ${ }^{[7]}$ (1900) performed cervical sympathectomy for the treatment of exophthalmic goiter. Francois-Frank ${ }^{[8]}$ advocated cervical sympathectomy for the treatment of glaucoma in 1899. In 1920 , Jonnesco ${ }^{[9]}$ treated angina pectoris with sympathectomy. Leriche ${ }^{[10]}$, in 1913, and Bruning ${ }^{[11]}$, in 1923, advocated sympathectomy for Raynaud's phenomenon and other vasospastic disorders. In 1920, Kotzareff $^{[12]}$ reported sympathectomy for the treatment of hyperhidrosis. The first lumbar sympathectomy was performed by Royle ${ }^{[13]}$ in 1923 . Diez ${ }^{[14]}$ and Adson ${ }^{[15]}$ applied lumbar sympathectomy for ischemic lesions of the lower limbs and delineated the pathophysiology of sympathectomy. In fact, sympathectomy remained the mainstay of therapy for ischemic lesions until the advent of direct arterial revascularization in the 1960 s.

In 1942, Hughes ${ }^{[16]}$ described the first thoracoscopic sympathectomy. In 1954, Krux ${ }^{[17]}$ reported 1400 thoracoscopic sympathectomies. Wittmoser ${ }^{[18]}$, a coworker of Krux, reported the single-puncture technique with the use of a special thoracoscope for sympathectomy in 1950. In fact, the studies by Wittmoser ${ }^{[19]}$ have been pivotal in the present understanding of the anatomy and the complex physiology of the dorsal thoracic sympathetic chain.

\section{ANATOMY AND PHYSIOLOGY OF THE SYMPATHETIC CHAIN}

The SNS is widely distributed throughout the body. Although afferent pathways exist and are important in relaying visceral sensory information to the central nervous system, the most clearly defined portions of the SNS are the efferent preganglionic and postganglionic fibers and their associated paravertebral ganglia.

The sympathetic chain extends from the base of the skull to the coccyx. It is located on each side of the spinal column and supplies nerves to the ipsilateral portion of the body. The sympathetic autonomic nervous system is a two-ganglion system [Figures 1-3]. The first ganglion is in the central nervous system, 


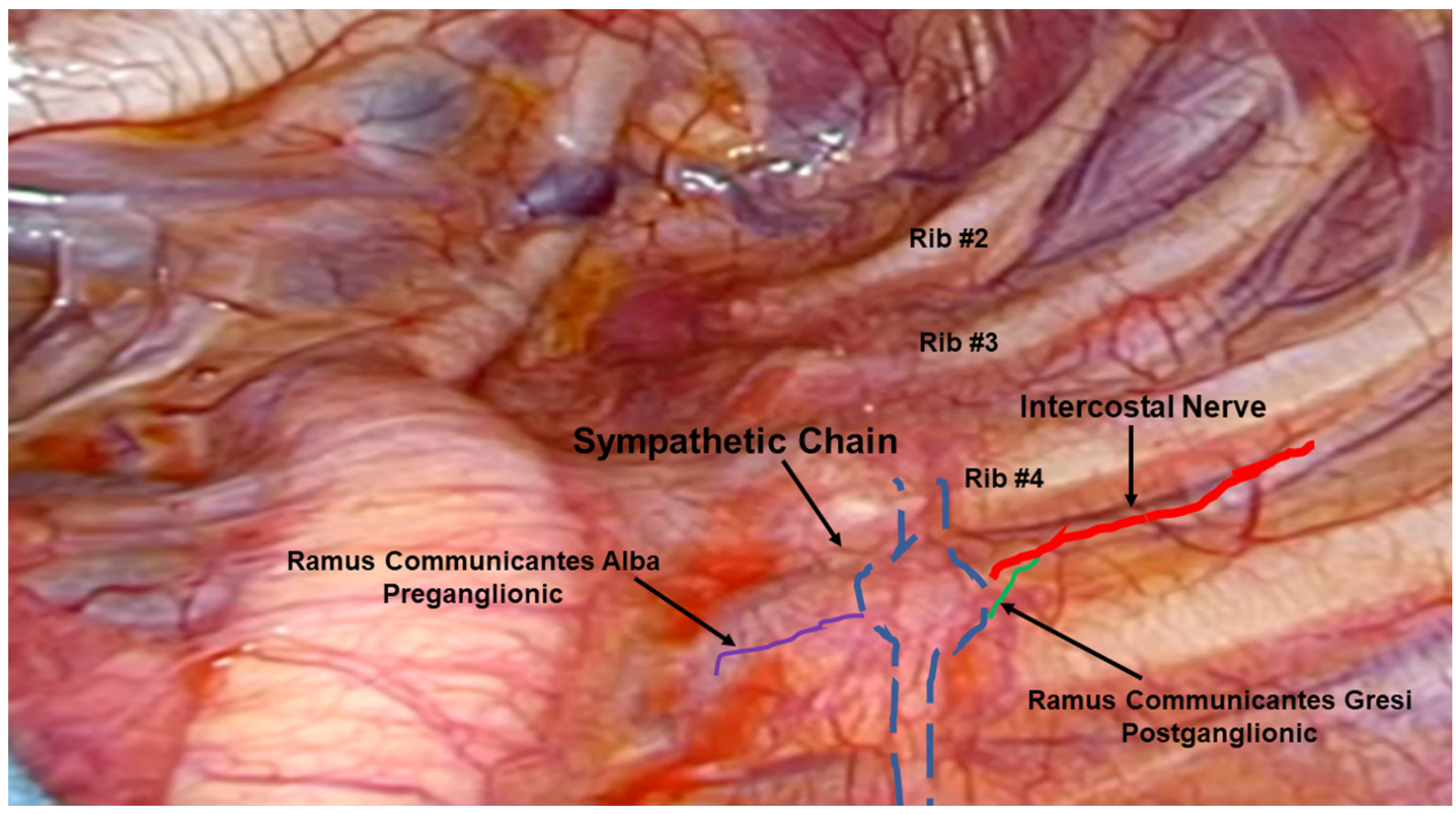

Figure 2. Thoracoscopic view of the left dorsal thoracic sympathetic chain. Axons from the first neuron (preganglionic) travel within the dorsal and ventral roots and form the preganglionic sympathetic fibers or rami communicantes albi (purple). Rami communicantes albi synapse with the second neuron within the sympathetic chain (blue), and postganglionic fibers or ramus communicantes grisei (green) travel with the intercostal nerves (red). The enlarged areas (ganglia) contain both nerve bodies of the second neuron and axons from neurons at other levels

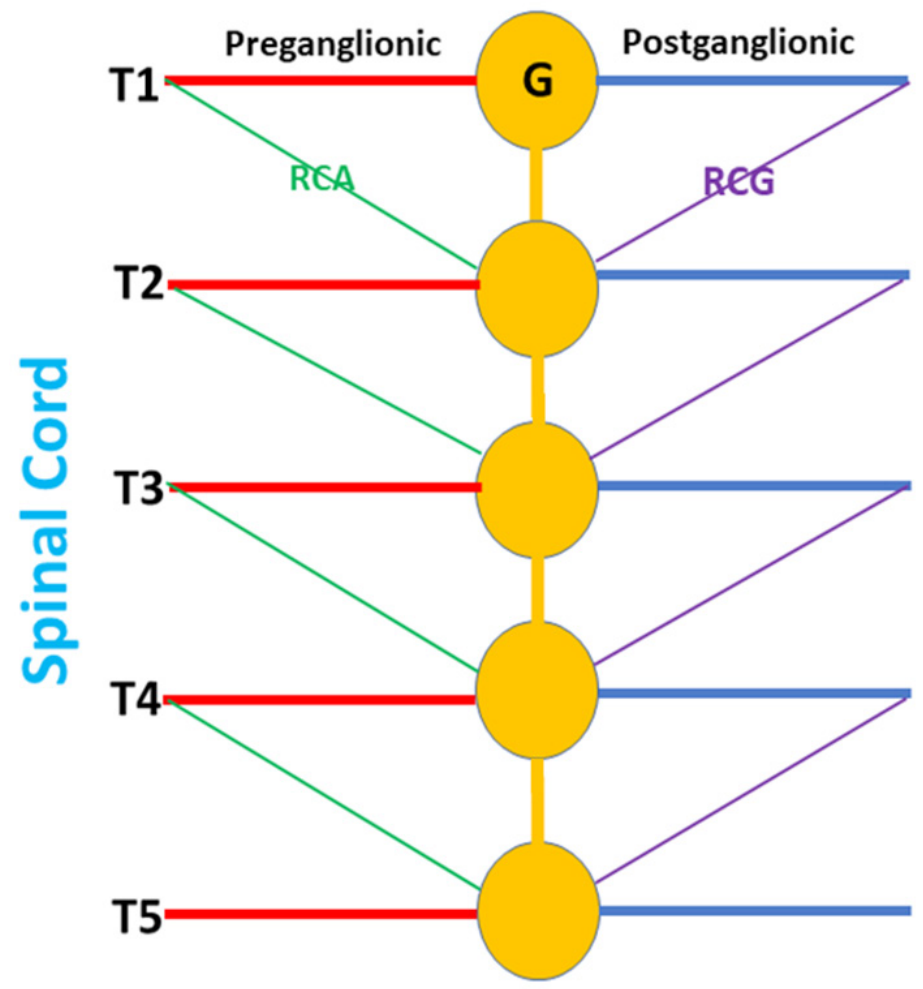

Figure 3. Schematic of the sympathetic chain for the purpose of surgical planning. RCA: rami communicantes albi; RCG: rami communicantes grisei; G: sympathetic ganglion 
more specifically in the spinal cord. The cell bodies that give rise to the preganglionic fibers of the SNS lie in the intermediolateral columns of the thoracolumbar spinal cord from C8 to L2 or L3. The second ganglion is located in the sympathetic chain or in peripheral ganglia. The short myelinated preganglionic fibers which represent the axonal component of the first ganglion leave the spinal cord within the anterior nerve roots, form white rami or rami communicantes albi (RCA), and synapse with the second ganglion. In the chest, the second ganglion is in the thoracic or dorsal sympathetic chain. Axons from the second ganglion in the sympathetic chain communicate with the peripheral organs via the gray rami or rami communicantes grisei (RCG). RCG carry postganglionic fibers back to the spinal nerves for distribution to the sweat glands, pilomotor muscles, and blood vessels of the skin and skeletal muscle. Twenty-two sets of paravertebral ganglia are paired on either side of the vertebral column, connected to the spinal nerves by the white and gray rami communicantes, and interconnected by nerve trunks to form the lateral chains. They include the upper and middle cervical ganglia, the stellate ganglia (fusion of inferior cervical and T1 ganglia), and the ganglia of the thoracic, abdominal, and pelvic sympathetic trunks. Unpaired prevertebral ganglia are found in the abdomen and pelvis near the ventral surface of the vertebral column. Splanchnic nerves represent preganglionic spinal nerves from the first order ganglia which pass through the sympathetic chain without connecting with the second order ganglia in the sympathetic chain. The second order ganglia for the splanchnic nerves are the peripheral vegetative ganglia and not the ganglia of the sympathetic chain ${ }^{[20]}$. The ganglia of the sympathetic chain are connected by the rami interganglionares (RI). The dorsal thoracic sympathetic chain is composed of sympathetic ganglia that correspond to a specific spinal segment. The dorsal sympathetic ganglia are connected by the RI. The preganglionic sympathetic nerves exit the spinal cord from the eighth cervical segment (C8) until the second or third lumbar segment (L2 or L3). Ganglia of the sympathetic chain are located at each of these segments. However, preganglionic spinal sympathetic segments not only supply the corresponding second ganglion, but they supply second ganglia located several segments above and below. Furthermore, Kuntz described the existence in some patients of an aberrant intrathoracic nerve $\mathrm{e}^{[21]}$. In these patients, the postsynaptic fibers travel with the second intercostal nerve to the brachial plexus. The $\mathrm{C} 8$ and $\mathrm{T} 1$ ganglia are fused into the stellate ganglion located above the apical pleural reflection. The stellate ganglion supplies postsynaptic sympathetic fibers to the ipsilateral face, eyelid, eyeball, and pupil. Interruption of the postganglionic sympathetic fibers from the stellate ganglion leads to Horner's syndrome. In a small percentage of individuals, the presynaptic sympathetic fibers from C8 and T1 spinal nerves travel down the RI before synapsing within the stellate ganglion. Interruption of the RI high in the sympathetic chain, even without damaging the stellate ganglion, can account for Horner's syndrome in these individuals. In addition, studies have shown that the stellate ganglion may have a greater role in the sympathetic innervation of the upper limb than has been known previously. This understanding may, in part, explain recurrence of hyperhidrosis in some individuals following thoracic sympathectomy ${ }^{[22,23]}$. The intrathoracic ganglia of the dorsal sympathetic chain are located in the intercostal spaces. The RI traverse the proximal portion of the ribs. The second and third sympathetic ganglia supply the hand. The third, fourth, and fifth thoracic sympathetic ganglia supply the axilla. The fourth and fifth ganglia supply the skin of the abdominal wall. The lower thoracic and upper lumbar ganglia supply the lower limbs. The main effect of an upper thoracic sympathectomy is to abolish sweating of the palms and the axilla. Sympathectomy produces a vasodilatory cutaneous effect. The improved skin blood flow is on the thermoregulatory and not nutritive level. With sympathectomy, the circulation in the muscles of the upper extremity is unaltered. It seems that chronic surgical sympathectomy does not change the vascular function of the forearm. T2-T3 ganglionectomy significantly decreases pulse rate and systolic blood pressure, reduces myocardial oxygen demand, increases left ventricular ejection fraction, and prolongs the QT interval. Sympathectomy appears to decrease lung volumes as well as diffusion capacity.

Although the cause of hyperhidrosis is unknown, it is theorized to be the result of overactivity of the central nervous system. The SNS has been likened to a river emanating from central sympathetic nuclei in the brain with tributaries that emanate from the second nuclei in the periphery and carry sympathetic impulses 
to the specific end organ. Sympathectomy has been likened to building a dam on the tributaries. As the flow of the central sympathetic activity remains unchanged, building a greater number of dams may cause the river to overflow through the open tributaries. This overflow of sympathetic activity through the intact sympathetic nerves, may be the analogy that best describes the condition of compensatory hyperhidrosis. In theory, by building fewer dams and allowing the flow of sympathetic activity to dissipate before building new dams, the rate of overflow in terms of compensatory hyperhidrosis may decrease. Compensatory hyperhidrosis may also dissipate. This hypothesis prompted the investigation of the role of staged bilateral selective dorsal sympathectomy.

\section{INDICATIONS FOR SYMPATHECTOMY}

Indications for sympathectomy include: intractable angina, arrhythmias, cardiomyopathy, complex regional pain syndrome, erythromelalgia, and some pancreatic and other painful abdominal pathologies, thromboangiitis obliterans (Buerger's disease), microemboli, primary Raynaud's phenomenon and Raynaud's phenomenon secondary to collagen diseases, paraneoplastic syndrome, frostbite, and vibration syndrome $e^{[20,24]}$. Presently, the most common indication for thoracic sympathectomy is primary hyperhidrosis, especially affecting the palm, and to a lesser degree, axilla and face, and for facial blushing.

Hyperhidrosis results from excessive stimulation of the eccrine glands ${ }^{[25]}$. Eccrine glands, which are present throughout the body, are most prevalent in the palms, axillae, and the plantar regions. Consequently, hyperhidrosis most commonly presents in the hands, axilla, and the feet. The upper extremity is most commonly affected, where $43 \%$ of patients have a combination of palm and axillary hyperhidrosis ${ }^{[26]}$. In $37 \%$ of patients, hyperhidrosis is localized to the axilla and in $20 \%$ only to the hand. Hyperhidrosis is seen in $1 \%$ of the population in the West. There is a high incidence in people of Japanese ancestry and Jews of North African, Yemeni, and Balkan descent. Although most cases of hyperhidrosis are idiopathic, secondary hyperhidrosis can be the result of hyperthyroidism, obesity, anxiety disorders, menopause, carcinoid syndrome, lymphoma, pheochromocytoma, diabetes, and tuberculosis ${ }^{[27]}$.

\section{Therapeutic options for the treatment of hyperhidrosis}

A number of approaches have been advocated for the management of hyperhidrosis.

\section{Nonsurgical management}

Aluminum chloride, glutaraldehyde, and tannic acid have been used as topical agents with disappointing results.

Since the sweat glands are innervated by the sympathetic postganglionic nerves and have acetylcholine as the primary neurotransmitter, systemic anticholinergics have been advocated to block postganglionic acetylcholine receptors ${ }^{[2]}$. Anticholinergic agents work by competitive inhibition of acetylcholine at the muscarinic receptor. Since, muscarinic receptors are present throughout the central and autonomic nervous system, the use of anticholinergics can be associated with widespread and varied side effects. Also, there are differences in the side effect profile of the different anticholinergic agents. Glycopyrrolate is a quaternary amine that has limited passage across lipid membranes such as the blood-brain barrier. Therefore, in contrast to agents such as atropine or scopolamine, which are tertiary amines and can easily penetrate lipid barriers, glycopyrrolate has fewer central nervous system side effects and may have less effect on the heart rate at lower doses ${ }^{[29]}$. Glycopyrrolate, oxybutynin and methantheline bromide are the most commonly used anticholinergics for the treatment of hyperhidrosis ${ }^{[30]}$. The most common side effect is dry mouth due to inhibition of salivary glands. Other side effects include: constipation, nausea, vomiting, bloating, loss of taste, mydriasis, cycloplegia, dry eyes, blurred vision, photophobia, reduced phlegm, urinary retention, erectile dysfunction, loss of libido, arrythmias, headache, dizziness, insomnia, drowsiness, confusion, seizures, pruritus, and urticaria. In addition, concurrent use with other medications 
with anticholinergic activity such as phenothiazines, antiparkinsonian drugs or tricyclic antidepressants, intensify the antimuscarinic effects and can increase side effects. Relative contraindications to the use of anticholinergics dugs are: glaucoma, obstructive uropathy, obstructive diseases of the GI tract, paralytic ileus, severe ulcerative colitis, and myasthenia gravis.

Beta blockers have been used to improve symptoms of social phobias and performance anxiety ${ }^{[31]}$.

Calcium channel blockers have also been used. The success of these techniques has been short-lived and limited.

Iontophoresis which attempts to coagulate eccrine glands by the use of electrical current has been used for palmar and plantar hyperhidrosis. This technique has had limited success ${ }^{[32,33]}$.

Botulinum toxin injection is the most studied hyperhidrosis treatment and demonstrates consistent improvement in Hyperhidrosis Disease Severity Scale (HDSS) scores and in sweat production as measured in the axillae and palms ${ }^{[34,35]}$. It may be considered first- or second-line therapy for hyperhidrosis affecting the axillae, palms, soles, or face. Botulinum toxins bind synaptic proteins, blocking the release of acetylcholine from the cholinergic neurons that innervate the eccrine sweat glands. The most commonly used preparation is onabotulinumtoxinA (Botox). OnabotulinumtoxinA is administered intradermally in the affected area. In most cases, treatment results last six to nine months. Adverse effects typically include injection-site pain and bruising, decreased grip strength when injected into the palms, and frontalis muscle weakness when used on the forehead.

A newer, noninvasive local treatment of axillary hyperhidrosis uses microwave technology ${ }^{[36]}$. The application of microwave energy destroys eccrine sweat glands by creating local heat, resulting in cellular thermolysis. This outpatient procedure is applied with a handheld transducer after mapping the axillae using a starch-iodine test. Local anesthesia is required. This treatment results in a decrease in the HDSS score of at least one point in $94 \%$ of patients and at least two points in $55 \%$ of patients ${ }^{[37]}$.

Fractionated microneedle radiofrequency is another emerging treatment in axillary hyperhidrosis ${ }^{[38]}$. During this procedure, microneedles are placed 2 to $3 \mathrm{~mm}$ under the skin, and radiofrequency energy is applied. This therapy results in a decrease in the HDSS score of at least one point in nearly $80 \%$ of patients $^{[39]}$.

\section{Alternative surgical therapies}

Surgical alternatives such as resection of the axillary sweat glands or subcutaneous curettage have been limited only to axillary hyperhidrosis. However, these techniques have had little acceptance due to the highly invasive nature of the procedures and the high complication rates and high relapse rates several months after the procedure ${ }^{[40,41]}$.

\section{Dorsal thoracic sympathectomy}

Nonsurgical methods for accomplishing dorsal thoracic sympathectomy have included: (1) percutaneous injection of phenol; (2) CT-guided injection of phenol; and (3) percutaneous radiofrequency thermal ablation ${ }^{[42-45]}$. These techniques have been hampered by very high recurrence rates shortly after the procedure. Dorsal sympathectomy has been the only treatment for hyperhidrosis that has resulted in longterm success.

Many surgical approaches have been described for dorsal thoracic sympathectomy. These have included: (1) the posterior thoracic approach; (2) cervical supraclavicular approach; (3) transthoracic approach; (4) transaxillary approach; (5) thoracoscopic approach; and (6) robotic thoracoscopic approach. 
Posterior thoracic approach: The classic posterior thoracic approach was popularized by Adson and modified by White ${ }^{[15]}$. This approach required partial rib resection and resulted in prolonged painful recovery.

Cervical supraclavicular approach: Telford devised a supraclavicular approach ${ }^{[46]}$. Although this approach obviated the pain associated with the rib resection, it was technically demanding and associated with complications. The transcervical route requires attention to the highly complex anatomy of the cervical region, and the complications are associated with injury to these structures. The advantages of this approach include the ability to perform a bilateral sympathectomy in one sitting, minimal pain, and good cosmetic results. With this approach, due to the inability to reach the lower portion of the sympathetic chain, the T4 ganglion cannot be excised. Therefore, this approach is not as efficacious for patients experiencing axillary hyperhidrosis.

Transthoracic approach: Goetz, Marr, and Palumbo advocated an anterolateral transthoracic approach ${ }^{[27]}$. Although this approach provided the best exposure and the most accurate sympathectomy possible, this technique did not gain popularity due to the significant morbidity associated with a thoracotomy.

Transaxillary approach: In 1954, Atkins ${ }^{[47]}$ described a transaxillary approach which became popular and is even used in some centers today. As has been noted, this technique suffers from the shortcoming of pain and lack of visualization through a very small transaxillary incision.

Thoracoscopic approach: The thoracoscopic approach to dorsal sympathectomy was used as far back as the 1940s. With the advent of advances in optics, lighting, and video endoscopic instrumentation, videoassisted thoracic surgery became the standard approach to dorsal sympathectomy ${ }^{[48,49]}$. Presently, there are four video-assisted approaches to enable dorsal thoracic sympathectomy.

Classic resection: This technique (ganglionectomy) [Figures 2 and 3] involves the resection of the entire sympathetic chain including the T2, T3, and T4 sympathetic ganglia with the intervening RI.

Clipping of the sympathetic chain: Proponents of this technique have emphasized the potential reversibility of the removal of the clip. However, clip removal has not been necessarily associated with recovery of sympathetic function ${ }^{[50]}$. Furthermore, some authors have postulated that clips may contribute to postoperative neuralgia ${ }^{[27,51]}$.

Thermal ablation of the dorsal sympathetic ganglion: This technique which can be accomplished using conventional electrocautery, diathermy with monopolar precise coagulation, or radiofrequency ablation has become the most commonly used technique ${ }^{[51]}$. The proponents of this technique have emphasized the ease of use, shorter operative times, the ability to perform bilateral sympathectomy, and the minimally invasive nature of the procedure. However, in a meta-analysis of published studies of thoracoscopic sympathectomy for hyperhidrosis, Hashmonai et al. ${ }^{[51]}$, showed that resection achieved superior results. It is due to the complex nature of the resection even with modern conventional video-assisted thoracic surgical techniques that the majority of surgeons choose thermal ablation of the sympathetic chain.

In 2011, the Society of Thoracic Surgeons expert consensus report for the treatment of hyperhidrosis was published $^{[52]}$. This report was based on 1,097 published articles in the world's literature on hyperhidrosis from 1991 to 2009. These studies suggested that primary hyperhidrosis of the extremities, axillae or face is best treated by endoscopic thoracic sympathectomy. Interruption of the sympathetic chain could be achieved either by electrocautery or clipping. This report emphasized the need for the adoption of an international nomenclature that would refer to the rib levels $(\mathrm{R})$ instead of the vertebral level at which 
the nerve is interrupted, and how the chain is interrupted, along with systematic pre- and postoperative assessments of sweating pattern, intensity and quality of life. This report suggested that the highest success rates occur when interruption is performed at the top of R3 or the top of R4 for palmar-only hyperhidrosis. R4 may offer a lower incidence of compensatory hyperhidrosis but moister hands. For palmar and axillary, palmar, axillary and pedal and axillary only hyperhidrosis, interruptions at R4 and R5 are recommended. The top of R3 is best for craniofacial hyperhidrosis.

\section{EXTENT OF SYMPATHECTOMY}

The success of dorsal thoracic sympathectomy is judged by: (1) High rate of relief of hyperhidrosis; (2) low rate of recurrence; and (3) low rate of compensatory hyperhidrosis and gustatory hyperhidrosis.

Invariably, the surgical procedures achieve symptomatic relief but are associated with compensatory hyperhidrosis in $50 \%-97 \%$ of patients ${ }^{[53-56]}$. Compensatory hyperhidrosis that occurs on the trunk and lower extremities following sympathectomy and gustatory hyperhidrosis, which refers to facial sweating associated with eating or olfactory sensation of hot spicy food, are significant complications of sympathectomy. As a result, several studies have attempted to determine whether limiting the extent of sympathectomy can impact the incidence of these two complications ${ }^{[57-64]}$. However, the results have been inconsistent, and randomized trials have not been performed. In 2000, Furlan et al. ${ }^{[65]}$ reviewed published series after sympathectomy. They reported a compensatory hyperhidrosis rate of $52.3 \%$, gustatory hyperhidrosis rate of $32.3 \%$, phantom hyperhidrosis of $38.6 \%$, and Horner's syndrome in $2.4 \%$ of patients. In 2200 patients undergoing ablation of T2 ganglion for palmar sweating and T3-4 ganglia for axillary sweating, Lin and associates showed successful sympathectomy in $99 \%$ of patients ${ }^{[66]}$. However, compensatory hyperhidrosis was noted in $88 \%$ of patients. It is important to note that the rate of compensatory hyperhidrosis depends on the rigor by which compensatory hyperhidrosis is defined. If compensatory hyperhidrosis is defined as "any increased amount of new sweating", as has been defined in many of the aforementioned studies, the rate of compensatory hyperhidrosis is very high. On the other hand, if some new compensatory sweating is tolerated by the patient and compensatory sweating is defined as "sweating that cannot be tolerated", the rate of compensatory hyperhidrosis will be much lower. The latter scenario is consistent with the experience of many surgeons. However, for the purpose of clarity and comparison of different surgical techniques, it is best to define compensatory in the most rigorous manner.

From these studies, a number of conclusions can be reached: (1) longer extent of dorsal thoracic sympathectomy is associated with greater risk of compensatory hyperhidrosis; (2) the severity of compensatory hyperhidrosis is decreased with staging of dorsal sympathectomy with unilateral sympathectomy accomplished a few weeks apart versus bilateral sympathectomy at the same setting; (3) the extent of compensatory hyperhidrosis is decreased with selective ramicotomy; and (4) incidence of Horner's syndrome is lower with transthoracic approach when sympathectomy is performed by dissection versus diathermy of the T2 ganglion or when sympathectomy is limited to below the T2 ganglion.

Landmark studies by Wittmoser ${ }^{[18]}$ and later by Friedel ${ }^{[20]}$ have determined the ideal extent of sympathectomy.

It has been postulated that limiting the extent of sympathectomy or sympathicotomy may decrease the rate of compensatory hyperhidrosis. The thoracic sympathetic chain is composed of both nerve bodies of the second sympathetic neuron as well as postganglionic axons from nerve bodies from other levels that travel within the chain. Microscopic examination of what macroscopically appears as a ganglion in the sympathetic chain reveals a combination of nerve bodies as well as communicating axons from other nerve bodies that travel up and down the chain. Based on this understanding, division of a single macroscopic ganglion does not result solely in the removal of the nerve bodies to that specific level, but in addition, 


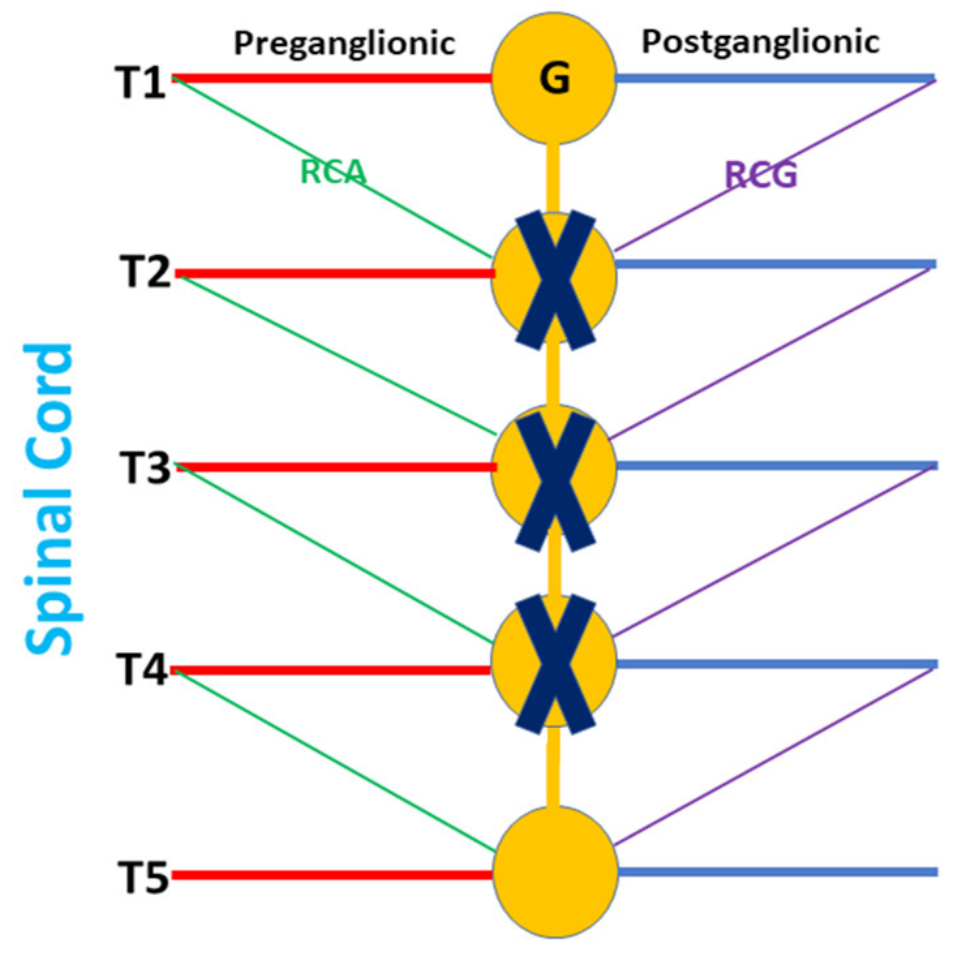

Figure 4. Classic ganglianectomy as depicted by resection of the sympathetic chain and ganglia (X) from T2 to T4. RCA: rami communicantes albi; RCG: rami communicantes grisei; G: sympathetic ganglion

results in the division of the axons from nerve bodies from other levels that travel through the chain. This realization may explain the variability of the extent of sympathectomy when the chain is divided, or specific macroscopic ganglia are removed.

The extent of sympathectomy correlates with the incidence of complications. Disruption of the chain (sympathectomy), or parts of the chain (sympathicotomy) or removal of selected ganglia will result in disruption of sympathetic activity to more than just the upper extremity. Only division of the postganglionic fibers that emanate from the chain and join the intercostal nerves, 2, 3 and 4, can assure selective disruption of sympathetic activity to the upper extremity. However, the efferent or postganglionic fibers at times travel behind the chain before emerging laterally to join the intercostal nerve. Therefore, to assure division of all the postganglionic fibers that travel with intercostal nerves 2, 3 and 4 to the upper extremity, the entire chain needs to be skeletonized and elevated away from the chest wall.

Selective postganglionic sympathectomy represents a more directed approach to sympathetic denervation of the upper extremity ${ }^{[6]}$. In this procedure, the sympathetic trunk and ganglia are left intact and only the rami that accompany intercostal nerves 2,3 and 4 to the upper extremity are divided selectively.

Friedel et al ${ }^{[26]}$ studied three possible techniques for selective sympathectomy: (1) thoracic resection of the sympathetic chain including T2, T3 and T4 ganglia and intervening IR. They referred this technique to as interganglionare. They concluded that this technique results in compensatory hyperhidrosis in the majority of patients. With this technique, Horner's syndrome is seen in a smaller percentage of patients compared to thermal ablation. The shortcoming of this technique is the possibility of leaving the postganglionic RCG with less than complete sympathectomy [Figure 4]; (2) division of the preganglionic RCA, while leaving the sympathetic chain intact [Figure 5]; and (3) division of postganglionic RCG for T2 to T4, while leaving the sympathetic chain intact [Figure 6]. 


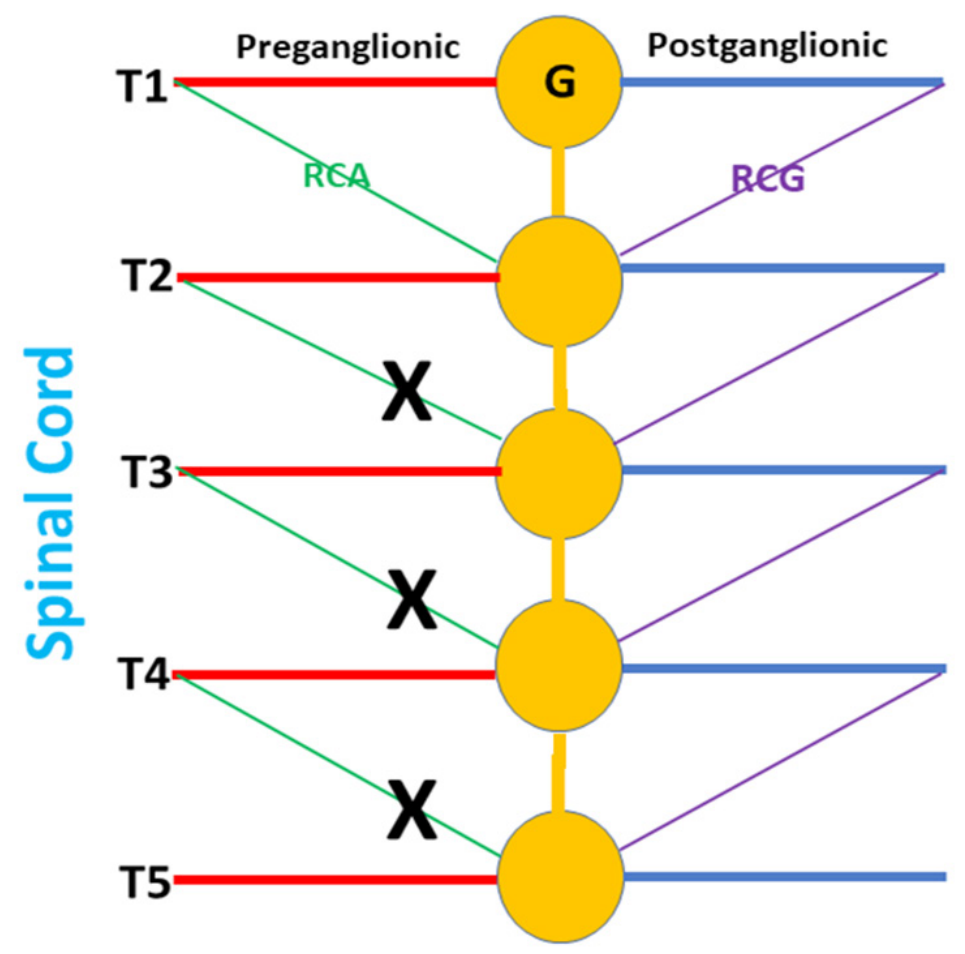

Figure 5. Preganglionic sympathectomy as depicted by division of the RCA from T2 to T4. The sympathetic chain is left intact. RCA: rami communicantes albi; RCG: rami communicantes grisei; G: sympathetic ganglion

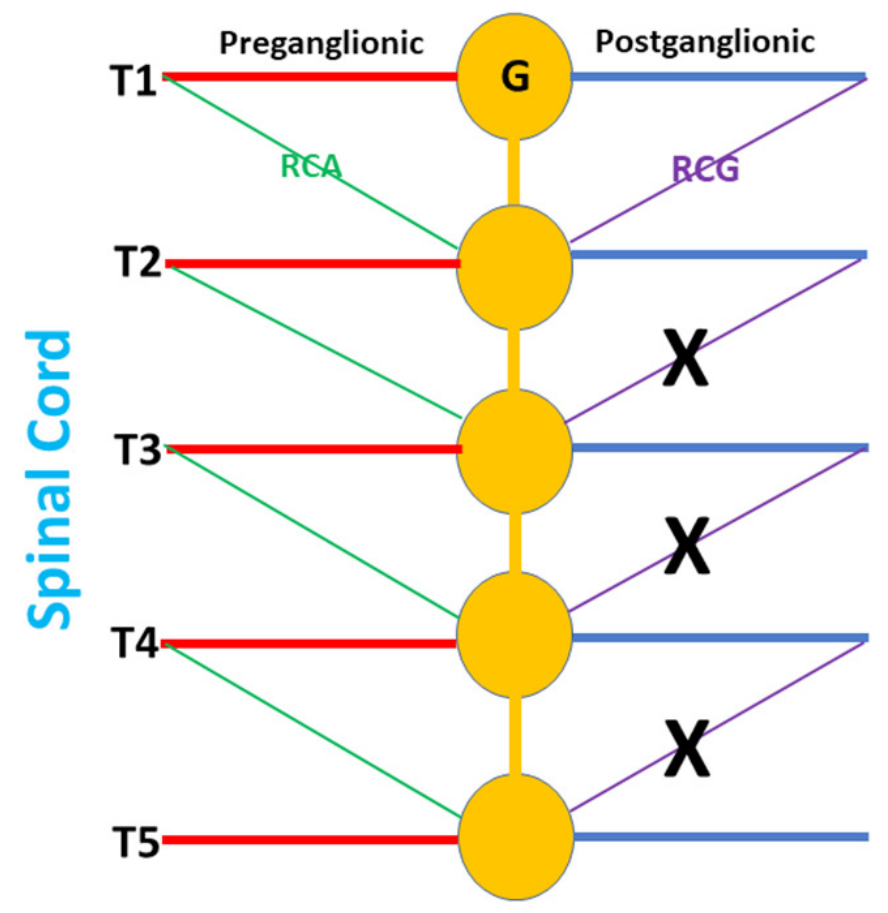

Figure 6. Postganglionic sympathectomy as depicted by division of the RCG from T2 to T4. The sympathetic chain is left intact. RCA: rami communicantes albi; RCG: rami communicantes grisei; G: sympathetic ganglion

Using the technique of selective sympathectomy with the division of the postganglionic RCG for T2 to $\mathrm{T} 4$, these authors showed a $95 \%$ reduction in perspiration and a compensatory hyperhidrosis rate of 


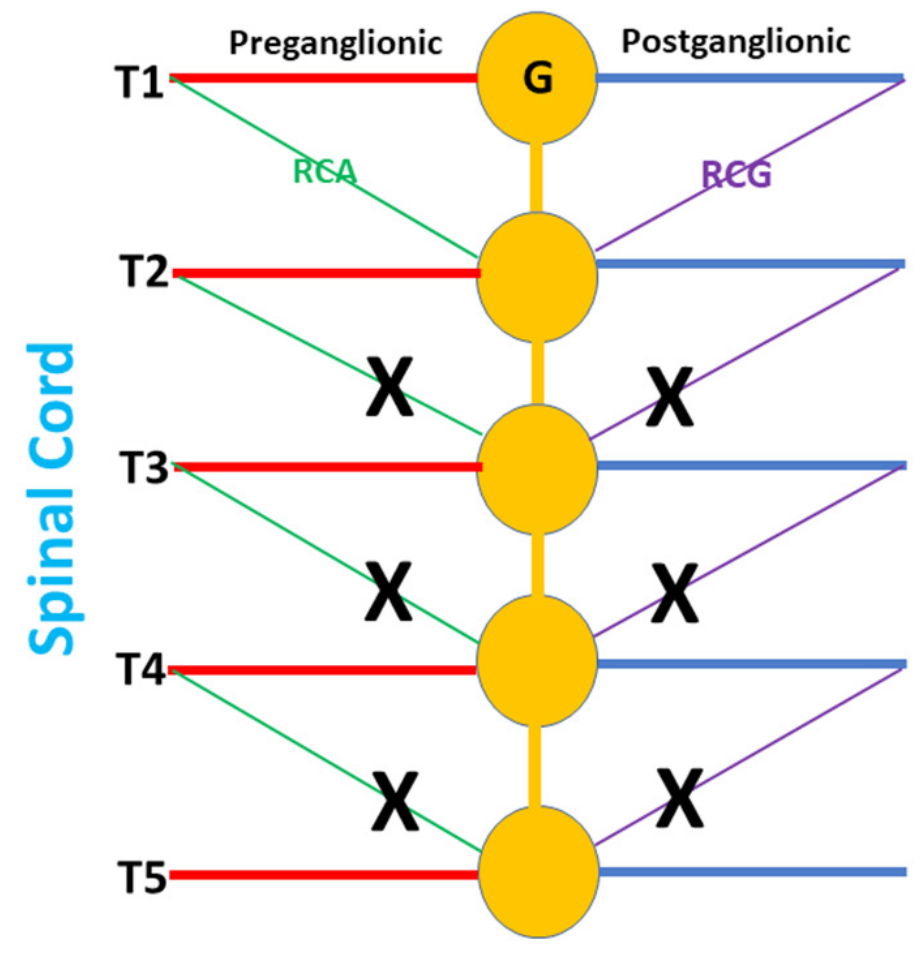

Figure 7. Selective dorsal sympathectomy as depicted by division of both the RCA and RCG from T2 to T4. The sympathetic chain is left intact. RCA: rami communicantes albi; RCG: rami communicantes grisei; G: sympathetic ganglion

$2.5 \%{ }^{[20]}$. Furthermore, with this technique, they did not report any patients with Horner's syndrome. Finally, this technique has resulted in the lowest reported rate of compensatory hyperhidrosis (16\%). However, subsequent studies with longer follow-up, showed that the results for reduction of perspiration were transient and that the long-term compensatory hyperhidrosis rate with this technique was $60 \%-70 \%$ and was comparable to other techniques. It has been suggested that the lack of sustained results with this technique was the result of poor visualization of the rami and incomplete ramicotomy as the preganglionic rami were left intact.

Using robotic technology and taking advantage of the 3-dimensional high-resolution magnified view and improved instrument maneuverability in the confined space, Coveliers and colleagues reported a series of patients who underwent simultaneous bilateral selective dorsal sympathectomy. In these patients, the preganglionic and postganglionic rami as well the communicating rami posterior to the sympathetic chain were divided and the sympathetic chain was left intact [Figure 7]. These authors used anhidrosis rather than reduction of perspiration as an endpoint. After two years follow-up, there was a $96 \%$ rate of anhidrosis and a $7.2 \%$ rate of compensatory sweating ${ }^{[6,69]}$.

As compensatory hyperhidrosis after sympathectomy is believed to result from redirection of sympathetic activity to other parts of the body, and has been shown to be related to the extent of sympathectomy, Gharagozloo et al ${ }^{[70]}$ hypothesized that staged bilateral robotic sympathectomy of one upper extremity followed by the other may result in even lower levels of compensatory hyperhidrosis. Gharagozloo et al. ${ }^{[70]}$ studied robotic staged bilateral selective sympathectomy (RSS) directed at the division of the preganglionic and postganglionic rami without interruption of the sympathetic chain. During RSS, the preganglionic and postganglionic sympathetic fibers and communicating rami to intercostal nerves 2,3 , and 4 were divided. The sympathetic chain was left intact [Figure 7]. Anhidrosis was used as an endpoint and was seen in $98 \%$ of patients. In turn, compensatory hyperhidrosis was defined rigorously as "any new sweating". At a mean follow up of $28 \pm 6$ months, $46 / 47$ (98\%) patients were free of sustained compensatory hyperhidrosis. 


\section{ROBOTIC SELECTIVE DORSAL SYMPATHECTOMY}

One of the shortcomings of the VATS techniques stems from the fact that the instruments are introduced through ports or small incisions which amount to holes in the chest wall. The instruments pivot at the entry holes and can be moved in four directions. The limited mobility of conventional endoscopic instruments, whether in the abdomen or the chest, has been referred to by some investigators as "chopstick surgery". The chopstick nature and the limited maneuverability of the effector instruments stems from the rigid shaft access fixed to the thorax by the entry hole. This technical shortcoming limits the surgeon in performing fine dissection and complex three-dimensional maneuvers. Pivoting instruments on the chest wall results in a large radius of curvature for the tip of the instrument and makes fine dissection in deep spaces such as the mediastinum very difficult and even dangerous.

Another shortcoming of the VATS technique is in the lack of the three-dimensional visualization. The surgeon has to use two-dimensional information from the video monitor to create a three-dimensional mental image. This fact requires significant experience and can prove to be a course of fatigue for the surgeon. Most importantly, using such indirect means of judging depth perception is rarely equivalent to binocular vision. In maneuvering the sympathetic chain away from the underlying vessels and determining the position of the RCG, binocular vision is paramount. The use of robotic technology obviates these difficulties. The Da Vinci robot (Intuitive Surgical) represents an ideal tool for the accurate dissection of the sympathetic chain away from the underlying vessels and identifying the preganglionic and postganglionic fibers to perform highly selective dorsal sympathectomy. The indispensable features of the Da Vinci robot for performing this procedure are: (1) the EndoWrist or the cable-driven wrist at the end of the robotic arm. The placement of the robotic arm through the VATS hole is comparable to and accomplishes the chopstick maneuvers performed by conventional VATS instruments. However, the EndoWrist at the distal end of the robotic arm is positioned in the confined spaces within the chest and brings 4_ more of freedom and six additional directions of movement compared to normal VATS techniques. The EndoWrist provides the surgeon with fine instrument maneuverability in a very confined space; (2) the Da Vinci robotic system is designed to provide downscaling from the motion of the surgeon's hand to that of the robotic instrument. This is invariable in dissecting fine and fragile intrathoracic structures. Furthermore, a $60 \mathrm{~Hz}$ motion filter is used to filter out any tremor in the surgeon's hand; and (3) the binocular robotic camera provides superb three-dimensional visualization by the nature of being mounted on the central robotic arm. It can be manipulated by the surgeon. The surgeon's ability to manipulate the camera and the arm recreates the natural biologic motion of the surgeon's head, eyes, and hands in providing optimal hand-eye coordination.

\section{Operative technique}

Room setup is depicted in Figure 8. Room setup is the same for both right- and left-sided procedures.

\section{Anesthesia}

Patients require single-lung ventilation. We prefer a left-sided double-lumen endotracheal tube to a bronchial blocker. In our experience, bronchial blockers are prone to dislodgment during the surgical procedure and require frequent manipulation which is difficult while the robot is in position. In addition, selective sympathectomy requires very precise dissection and a controlled visual field without intrusion from the inflating lung. Longer tubing is required during the robotic procedure as the anesthesiologist will occupy a more remote position away from the patient. The patient is placed in a full lateral decubitus position. We prefer to perform highly selective sympathectomy beginning with the most affected side, returning after any compensatory hyperhidrosis has subsided or plateaued in severity. The table is flexed to open the intercostal spaces and the position of the double-lumen tube is reconfirmed after final positioning. The patient then is prepared and draped in a routine manner. The superior portion of the drape is allowed to cover the patient's head. After port placement, the table is unlocked and rotated 30 degrees from its normal position to facilitate the positioning of the robot over the patient's head. 


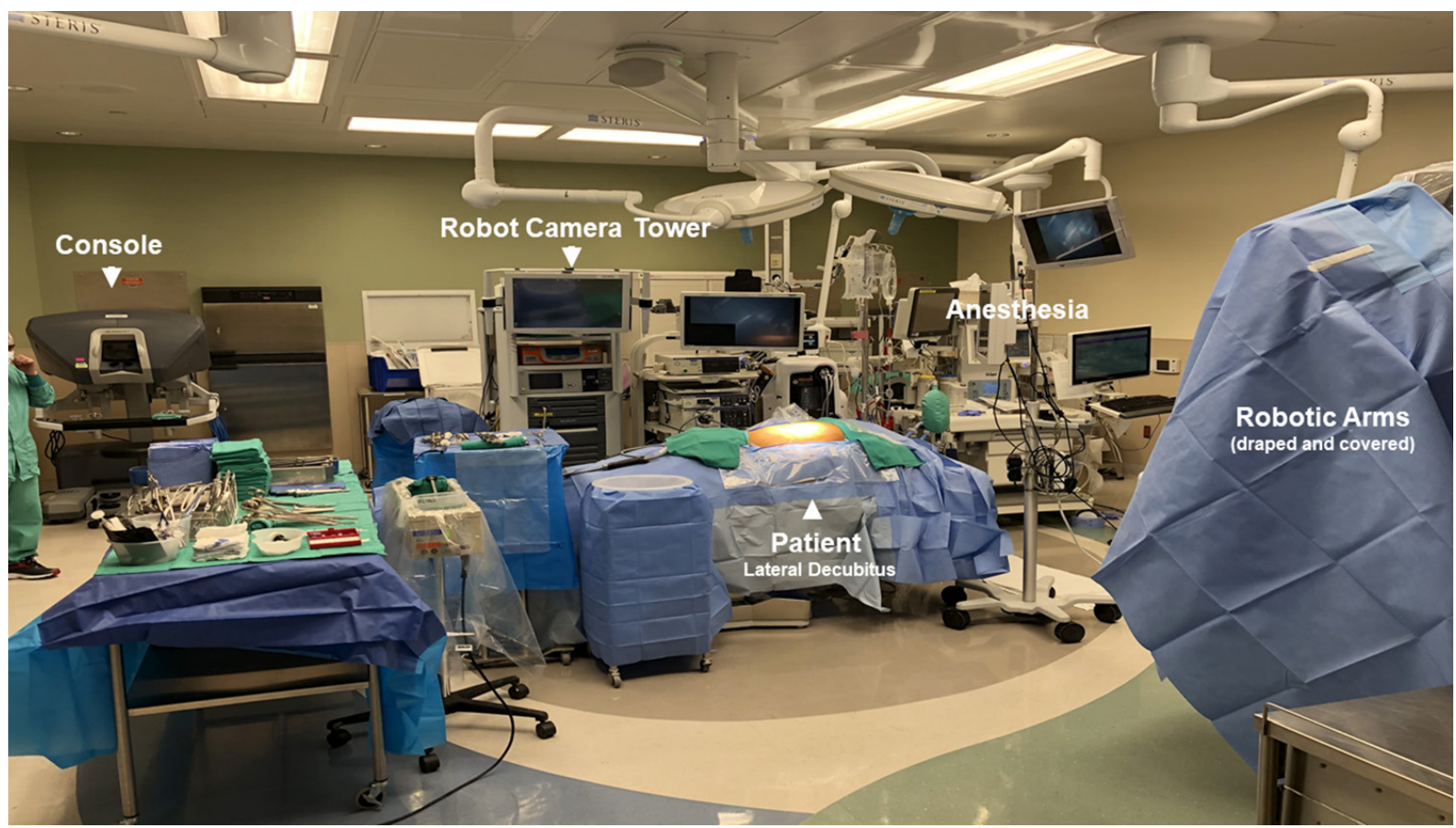

Figure 8. Room setup. The room setup is the same for right- or left-sided approach

The surgeon stands facing the patient's back. Pleural entry is with a Hassan needle. Saline is infused and care is taken to look for easy egress of the saline from the needle. If there is any question of pleural adhesions, we use a Visiport Instrument (Medtronic Inc. Norwalk, CT) for entry into the pleural space under direct vision. A line is drawn from the tip of the scapula to the costal arch. This corresponds to the midaxillary line. Port \#1, the camera port (\#1) is placed in the sixth intercostal space in the midaxillary line [Figures 9-11]. Port \#2, 8-mm trocar (\#2) is placed in the third intercostal space in the anterior axillary line. For approach to the sympathetic chain in the right chest, this port will be used by the right robotic arm, and for the left-sided sympathetic chain, this port will be used by the left robotic arm. Port \#3, $8 \mathrm{~mm}$, (\#3) is placed in the fifth intercostal space posterior axillary line. For approach to the sympathetic chain in the right chest, this port will be used by the left robotic arm, and for the sympathetic chain in the left chest, this port will be used by the right robotic arm. An Auxiliary (AP) $2 \mathrm{~cm}$ incision is made in the sixth intercostal space in the anterior axillary line. A retractor (Endopaddle Retract, Medtronic Inc., Norwalk, CT. USA) is passed through this port and used to retract the lung medially. The retractor is attached to the operating table by a self-retaining system (Mediflex, Velmed Inc., Wexford, PA, USA). Carbon dioxide insufflation is not used. At this point, the robot is brought into the operating field over the patient's head. The camera arm with a 30-degree down-viewing binocular camera is introduced through port \#1. In the right chest, the right robotic arm with the robotic hook cautery is positioned through port \#2, and the left robotic arm with the robotic DeBakey forceps is positioned through port \#3. In the left pleural space, the right robotic arm enters the pleural space through port \#3 and the right robotic arm enters the pleural space through port \#2 [Figure 12]. The sympathetic chain is identified. The ribs are counted, electrocautery marks are placed away from the sympathetic ganglia to specify the position of ganglia $\# 2$, \#3, and \#4. The portion of the sympathetic chain between ganglia \#4 and \#5 overlying rib \#5 is identified, dissected with the hook cautery. The sympathetic chain is encircled and lifted with a rubber atraumatic vascular loop. The postganglionic fibers (RCG) can be identified easily as the fibers emanating from the chain towards the distal portion of the ribs. These fibers are divided using electrocautery. The preganglionic fibers entering the sympathetic chain are also divided and the chain is elevated. Dissection is carried to the level of the second sympathetic ganglion. Following the division of the preganglionic and postganglonic fibers, the 


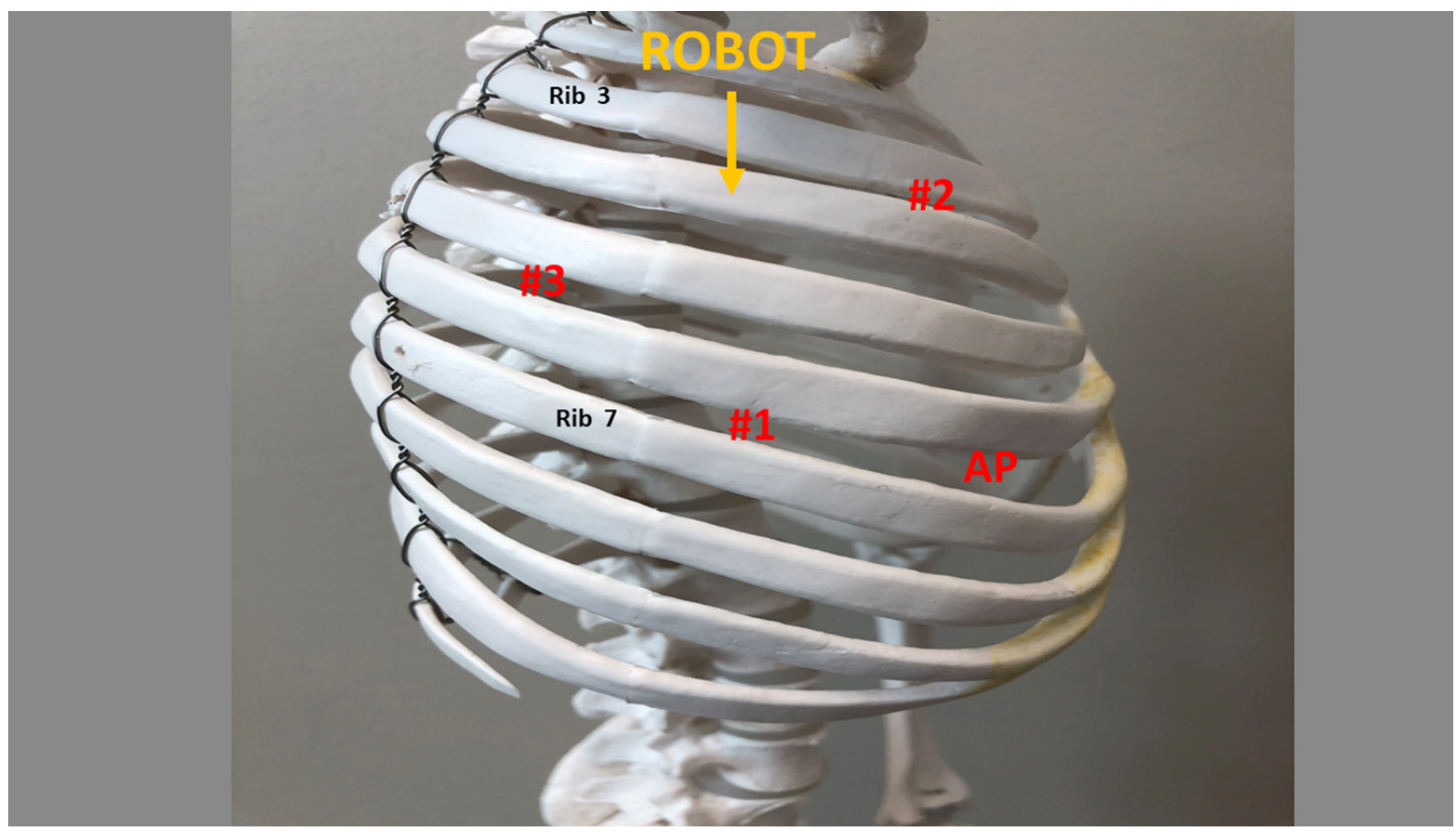

Figure 9. Schematic depicting port placement during robotic selective dorsal sympathectomy. Right chest. AP: accessory port

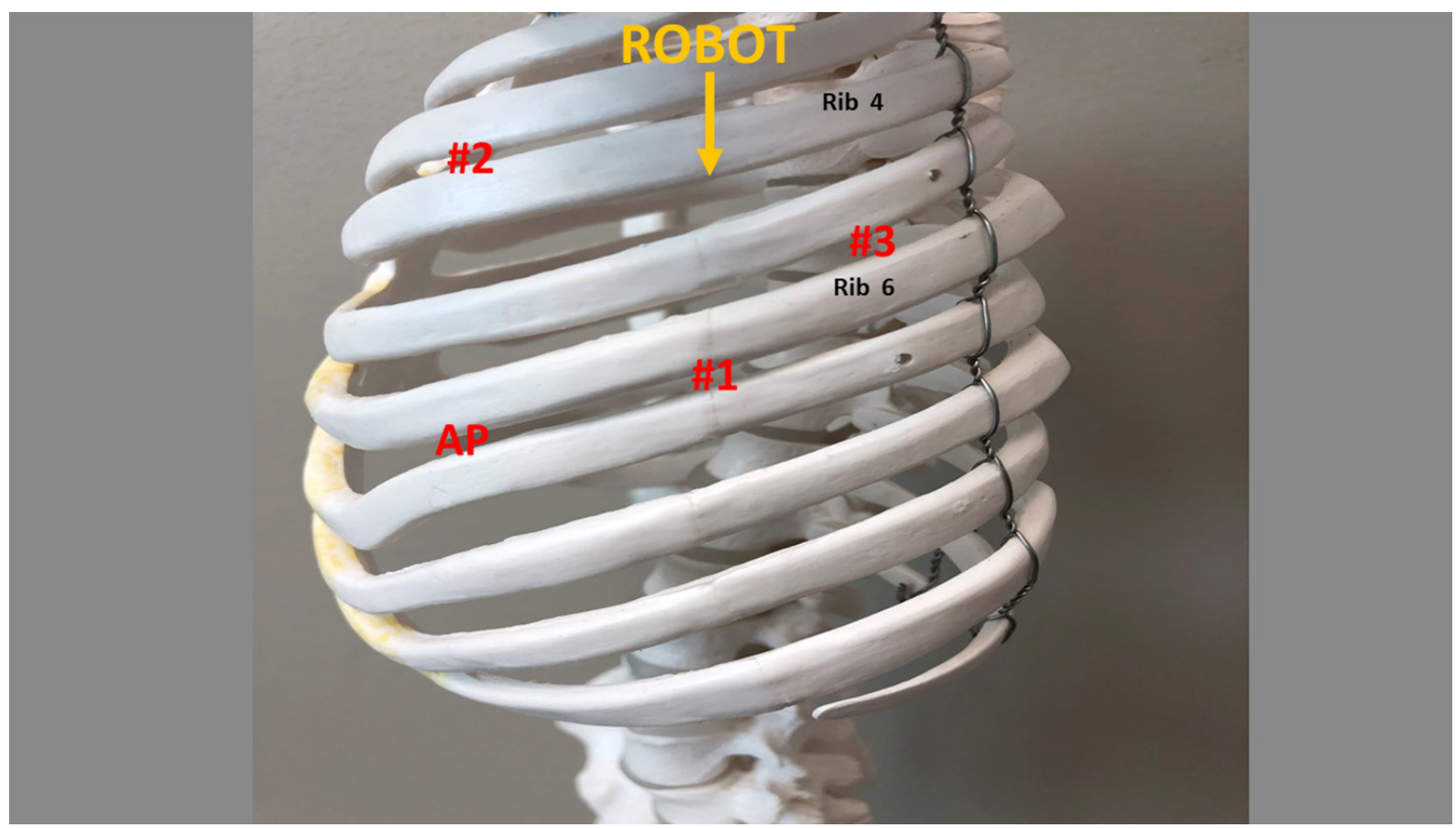

Figure 10. Schematic depicting port placement during robotic selective dorsal sympathectomy. Left chest. AP: accessory port

sympathetic chain is elevated and all posterior attachments to the ribs are severed using electrocautery. This maneuver disconnects the RI which are communicating fibers between the ganglia. Following completion of the highly selective sympathectomy, flexible drain is positioned posteriorly in the pleural space and brought out through the AP. On-Q subpleural catheters are placed traversing T2 to $\mathrm{T} 8^{[71]}$. All patients are extubated and are returned to the recovery room. 


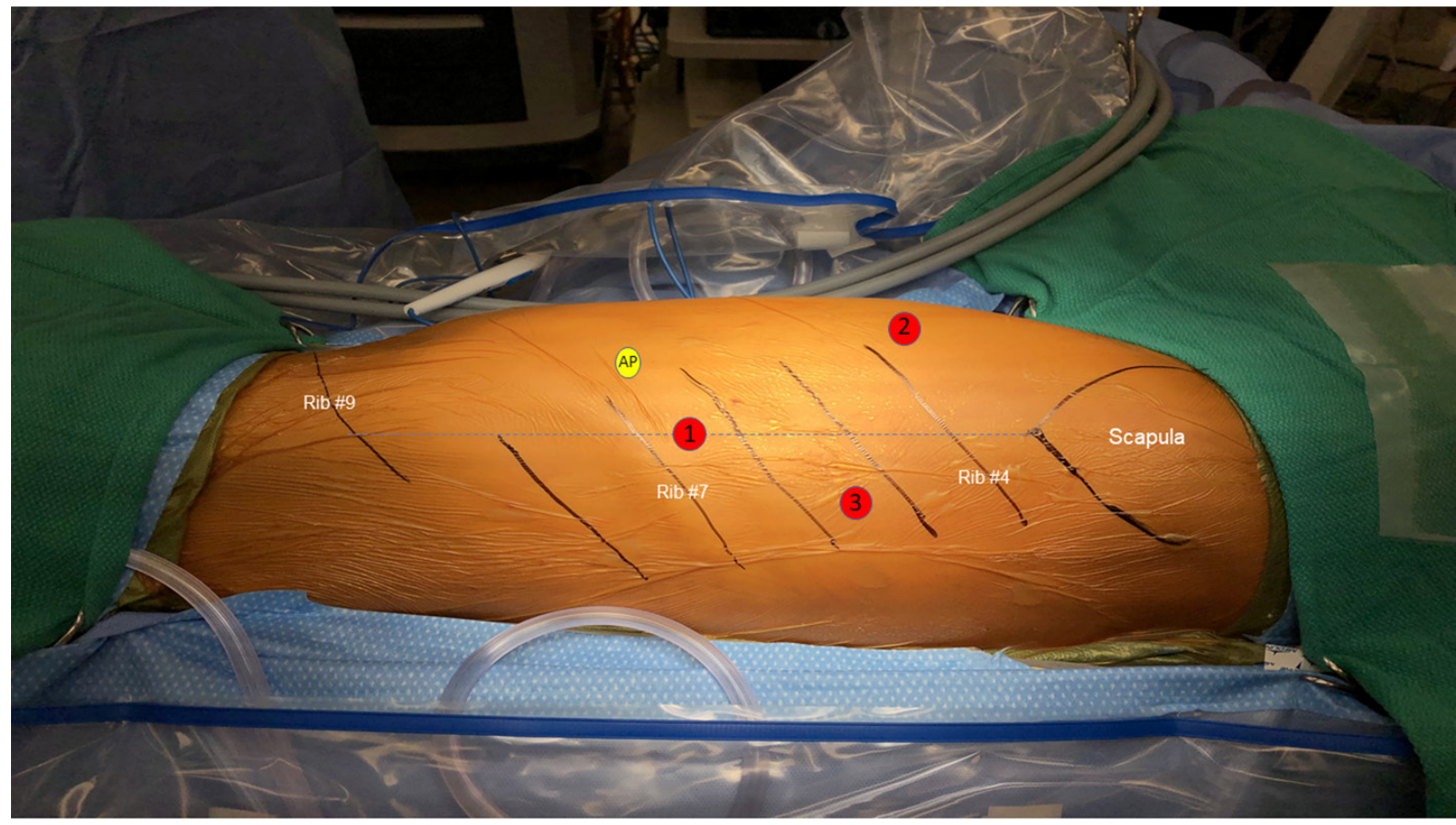

Figure 11. Patient undergoing left selective dorsal sympathectomy. Pt is in a decubitus position. A line is drawn from the tip of the scapula to the costal arch. This denotes the midaxillary line and highest point in the chest. Trocars are depicted by red circles. AP: accessory port

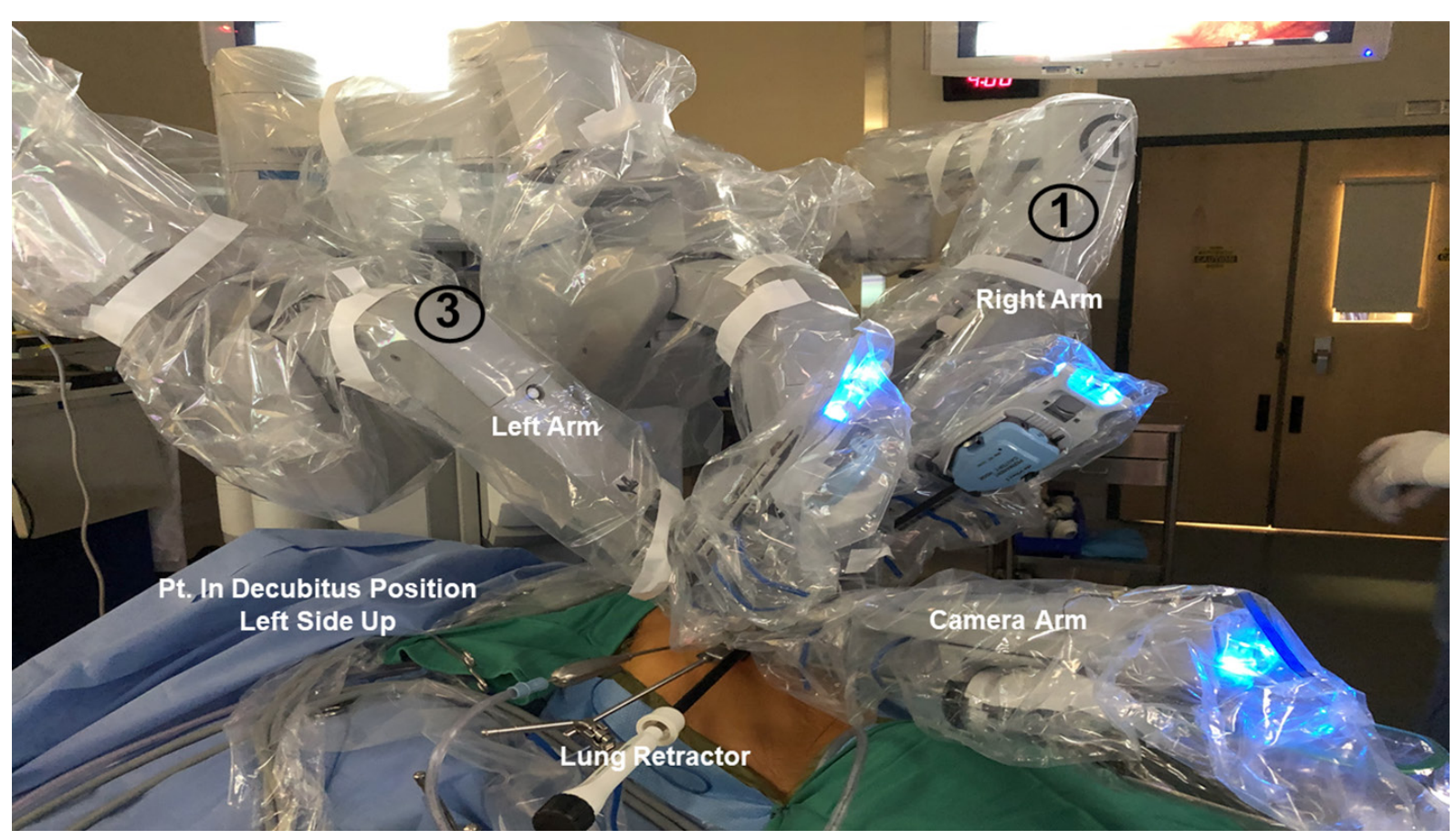

Figure 12. Left robotic selective sympathectomy. Intraoperative photograph depicts the robot in position. Three robotic arms are used

\section{CONCLUSION}

Significant controversies surround the minimally surgical treatment of hyperhidrosis. Historically, the interruption of the sympathetic chain has been associated with relief of hyperhidrosis but with high rates 
of debilitating compensatory hyperhidrosis. Greater understanding of the anatomy and physiology of the sympathetic chain, and advances in minimally invasive surgical techniques and instruments have clarified many of the controversies. Selective division of the preganglionic and postganglionic sympathetic fibers from T2-T4 without interruption of the sympathetic chain has been associated with the greatest rate of anhidrosis and the lowest rates of compensatory hyperhidrosis. In more recent studies, there are indications that a bilateral staged approach may be preferable to bilateral simultaneous approach to selective dorsal sympathectomy for hyperhidrosis.

Although the results of bilateral staged robotic selective dorsal sympathectomy appear to be superior to that of previous procedures, many surgeons question the cost-effectiveness of the robotic procedure. The comparison of the hospital cost and clinical effectiveness of sympathectomy by video-assisted surgery (VATS) (thoracoscopic) or robotics has not been performed. However, a number of studies have studied the hospital cost and clinical effectiveness of robotic versus thoracoscopic and open lobectomy. Nishimura reviewed the literature for the cost of robotic lobectomy ${ }^{[72]}$. Nine of the 18 published articles compared the cost of robotic lobectomy with VATS alone. All of these studies found a significantly higher total cost in the robotic group when compared to VATS. The intraoperative costs or charges were significantly higher in the robotic group. Interestingly, Kneuertz et al. ${ }^{[73]}$ performed a propensity score-weighted comparison of the cost and perioperative outcomes of the three approaches to lobectomy for a 5-year period at a tertiary referral center ${ }^{[73]}$. The propensity score comparison showed no statistical difference for the direct hospital cost between the three groups (robotic $\$ 17,223$, VATS $\$ 17,260$ and open $\$ 18,075$ ). In this study, postoperative complications and prolonged hospital stay added considerable hospital expenses. They concluded that the cost of robotic procedures needs to be placed in the context of the surgical outcomes. Specifically, in terms of the comparison of the cost of robotic versus VATS selective sympathectomy for hyperhidrosis, the increased cost of robotic instrumentation needs to be viewed within the perspective of the rate of anhidrosis and compensatory hyperhidrosis.

Finally, many experienced surgeons can perform a VATs sympathectomy in one hour or less, with two 5 -mm ports and usually in the outpatient setting. Comparison of this approach to staged robotic selective staged sympathectomy needs to be viewed in the context of the rates of anhidrosis and perhaps most importantly the rate of compensatory hyperhidrosis, and viewed both from the perspective of the patient and that of the surgeon. Clearly the answer will be provided by a well-designed, prospective randomized approach which will compare the VATS to the robotic approach with very rigorous definition of anhidrosis and compensatory hyperhidrosis with inclusion of cost and quality of life considerations.

\section{DECLARATIONS}

\section{Authors' contributions}

Both authors contributed equally to the preparation of the manuscript.

\section{Availability of data and materials}

Not applicable.

\section{Financial support and sponsorship}

None.

\section{Conflicts of interest}

Both authors declared that there are no conflicts of interest.

\section{Ethical approval and consent to participate}

Not applicable. 


\section{Consent for publication}

Not applicable.

\section{Copyright}

(c) The Author(s) 2020.

\section{REFERENCES}

1. Royle JP. History of sympathectomy. Aust N Z J Surg 1999;69:107-12.

2. Brown WL. The Involuntary Nervous System. London: Longman, Green and Co.; 1916.

3. Bernard C. Sur les effets de la section de la portion cephalous du grand sympathique. Comptes rend Soc Biol 1852;4:168-70.

4. Brown-Sequard CE. Experimental researches applied to physiology and pathology. M Exam 1852;8:481, 548,617,698.

5. Alexander W. The treatment of epilepsy. Edinburgh: Cambridge University Press; 1889. p228.

6. Jonnesco T. Resecta totala si bilaterala a simpaticulu cervical in cazuri de epilepsie si gusa exophthalmia. Romania Med 1896;4:479-96.

7. Jaboulay M. Le traitement de quelques troubles trophiques du pied et de la jambe par la dénudation de l'artère fémorale et la distension des nerfs vasculaires. Lyon Med 1899;91:467-8.

8. Francois-Frank M. Signification ohysiologique de la resection du sympathique dans la maladie de Basedow, l'epilepsie, l'idiotie etle glaucoma. Bull Acad Med Paris 1899;41:565-94.

9. Jonnesco T. Angine de poi trine guerie par le resection du sympathique cervicothoracique. Bull Acad Med Paris 1920;84:93-102.

10. Leriche R. De elongation et de la section des nerfs perivasculaires dans certain syndrome douloureux d'origine arterielle et dans quelque troubles trophique. Lyon Chir 1913;10:378-82.

11. Bruning F. Zur technik der kombinierten resectionsmethode samtlicher sympathischen nervenbahnen am hasle. Zentralbl Chir 1923;5:1056-9.

12. Kotzareff A. Resection partielle du tronc sympathique cervical droit pour hyperhidrose unilaterale. Rev Med Suisse Rom 1920;40:111-3.

13. Royle ND. A new operative procedure in the treatment of spastic paralysis and its experimental basis. Med J Aust 1924;1:77-86.

14. Diez J. Un Nuevo methdo de simpatectomia periferica para el tratamiento de las afecciones troficas y gangrenosas de los miembros. Bol Soc Cir Buenos Aires 1924;8:792-806.

15. Adson AW, Brown GE. treatment of Raynaud's disease by lumbar ram section and ganglionectomy's and per vascular sympathetique neurectomy of the common iliacs JAMA 1925;84:1908-10.

16. Hughes J. Endothoracic sympathectomy. Proc Roy Soc Med 1942;35:585-6.

17. Kux M. Thoracic endoscopes sympathectomy in palmar and axillary hyperhydrosis. Arch Surg 1978;113:264-6.

18. Wittmoser R: Toracoscopic Sympathectomy and agronomy. In Operative manual of endoscopes Surgery Cuschieri A et. Al. (eds), Berlin, Sringer Verlag, 1992.

19. Schurr MO, Buess G. Wittmoser's technique of thoracoscopic sympathectomy and agronomy. Endosc Surg 1993;1:266-70.

20. Friedel G, Linder A, Toomes H. Sympathectomy and agronomy. In: Minimal Access Thoracic Surgery, In: Mannke K, Rosin RD, editors. London: Chapman Hall; 1998. pp. 67-83.

21. Kuntz A. Distribution of the sympathetic rami to the brachial plexus. Its relation to sympathectomy affecting the upper extremity. Arch Surg 1927; $15: 871-7$.

22. Carron H, Litwiller R. Stellate ganglion block. Anesth Analges 1975;54:567-70.

23. Pather S, Partar P, Sengh B, Satyapal KS. Cervico-thoracic ganglion: its clinical implications. Clin Anat 2006;19:323-6.

24. Hashmonai M, Cameron AE, Licht PB, Hensman C, Schick CH. Thoracic sympathectomy: a review of current indications. Surg Endosc 2016;30:1255-69.

25. Drucker WR, Hubay CA, Holden WD, Bukovnic JA. Pathogenesis of post-traumatic sympathetic dystrophy. Am J Surg 1959;97:454-65.

26. Friedel G, Linder A, Toomes H. Selective video-assisted thoracoscopic sympathectomy. Thorac Cardiovasc Surg 1993;41:245-8.

27. Hazelrigg SR, Mack MJ. Surgery for autonomic disorders. Thoracoscopic Surgery. In: Kaiser LR, Daniel TM, editors. Boston: Little, Brown and Company; 1993. pp. 189-202.

28. Lakraj AD, Moghimi N, Jabbari B. Hyperhidrosis: anatomy, pathophysiology and treatment with emphasis on the role of botulinum toxins. Toxins 2013;5:821-40.

29. Bajaj V, Langtry JA. Use of oral glycopyrronium bromide in hyperhidrosis. Br J Dermatol 2007;157:118-21.

30. Gish P, Mosholder AD, Truffa M, Johann-Liang R. Spectrum of central anticholinergic adverse effects associated with oxybutynin: comparison of pediatric and adult cases. J Pediatr 2009;155:432-4.

31. Schneier RF. Social anxiety disorder. New Engl J Med 2006;355:2702.

32. Solish N, Bertucci V, Dansereau A, Hong HC, Lynde C, et al. A Comprehensive approach to the recognition, diagnosis, and severitybased treatment of focal hyperhidrosis: recommendations of the canadian hyperhidrosis advisory committee. Dermatologic Surgery 2007;33:908-23.

33. Levitt F. Treatment of hyperhydrosis by tap water iontopheresis. Cutis 1980;26:192.

34. Weinberg T, Solish N, Murray C. Botulinum neurotoxin treatment of palmar and plantar hyperhidrosis. Dermatol Clin 2014;32:505-15.

35. Lowe NJ, Glaser DA, Eadie N, Daggett S, Kowalski JW, et al. Botulinum toxin type A in the treatment of primary axillary hyperhidrosis: a 52-week multicenter double-blind, randomized, placebo-controlled study of efficacy and safety. J Am Acad Dermatol 2007;56:604-11. 
36. Jacob C. Treatment of hyperhidrosis with microwave technology. Semin Cutan Med Surg 2013;32:2-8.

37. Hong HC, Lupin M, O’Shaughnessy KF. Clinical evaluation of a microwave device for treating axillary hyperhidrosis. Dermatol Surg 2012;38:728-35.

38. Fatemi Naeini F, Abtahi-Naeini B, Pourazizi M, Nilforoushzadeh MA, Mirmohammadkhani M. Fractionated microneedle radiofrequency for treatment of primary axillary hyperhidrosis: a sham control study. Australas J Dermatol 2015;56:279-84.

39. Abtahi-Naeini B, Naeini FF, Saffaei A, Behfar S, Pourazizi M, et al. Treatment of primary axillary hyperhidrosis by fractional microneedle radiofrequency: is it still effective after long-term follow-up? Indian J Dermatol 2016;61:234.

40. Glaser DA, Galperin TA. Local procedural approaches for axillary hyperhidrosis. Dermatol Clin 2014;32:533-40.

41. Lawrence CM, Lonsdale Eccles AA. Selective sweat gland removal with minimal skin excision in the treatment of axillary hyperhidrosis: a retrospective clinical and histological review of 15 patients. Br J Dermatol 2006;155:115-8.

42. Dondelinger RF, Kurdziel JC. Percutaneous phenol block of the upper thoracic sympathetic chain with computed tomography guidance. A new technique. Acta radiol 1987;28:511-5.

43. Adler O, Engel A, Sargeno D. Palmar hyperhidrosis treated by percutaneous transthoracic chemical sympathicolysis. Eur Radiol 1994;4:57-62.

44. Wilkinson HA. Radiofrequency percutaneous upper thoracic sympathectomy. Technique and review of indications. N Engl J Med 1984;311:34-8.

45. Wilkinson HA. Percutaneous radio frequency upper thoracic sympathectomy. Neurosurgery 1996;38:715-25.

46. Telford ED. The technique of sympathectomy. Br J Surg 1935;23:448-50.

47. Atkins H. Sympathectomy by axillary approach. Lancet 1954;1:538.

48. Raposio E, Caruana G. Video-assisted thoracic Sympathicotomy for the treatment of palmar and Axillary Hyperhidrosis. A 17-year Experience. Surg Laparosc Endosc Percutan Tech 2015;25: 417-9.

49. Raposio E, Bellini E, Grieco MP. Minimally Invasive dorsal sympathicotomies for the treatment of hyperhidrosis: palmar microcirculatory assessment as an intraoperative aid. Eur J Plast Surg 2018;41:4417-50.

50. Teleranta T. Secondary sympathetic chain reconstruction after endoscopes thoracic sympathectomy. Eur J Surg 1998;1:1-8.

51. Hashmonai M, Assalia A, Kopelman D. Thoracoccopic sympathectomy for palmar hyperhydrosis. Ablate or resect? Surg Endosc 2001; 15:435-41.

52. Cerfolio RJ, De Campos JR, Bryant AS, Connery CP, Miller DL, et al. The Society of thoracic surgeons expert consensus for the surgical treatment of hyperhidrosis. Ann Thorac Surg 2011;91:1642-8.

53. Riet M, Smet AA, Kuiken H, Kazemier G, Bonjer HJ. Prevention of compensatory hyperhidrosis after thoracoscopic sympathectomy for hyperhidrosis. Surg Endosc 2001;15:1159-62.

54. Neumayer C, Zacherl J, Holak G, Függer R, Jakesz R, et al. Limited endoscopic thoracic sympathetic block for hyperhidrosis of the upper limb: reduction of compensatory sweating by clipping T4. Surg Endosc 2004;18:152-6.

55. Lin TS. Endoscopic clipping in video-assisted sympathetic blocade for axillary hyperhydrosis. An analysis of 26 cases. Surg Endosc 2001; $15: 126-8$.

56. Lin CC, telaranta T. Lin-Telaranta classification: the importance of different procedures for different indications in sympathetic surgery. Ann Chir Gynaecol 2001;90:161-6.

57. Schmidt J, Bechara FG, Altmeyer P, Zirngibl H. Endoscopic thoracic sympathectomy for severe hyperhidrosis: impact of restrictive denervation on compensatory sweating. Ann Thorac Surg 2006;81:1048-55.

58. Gossot D, Toledo L, Fritsch S, Célérier M. Thoracoscopic sympathectomy for upper limb hyperhidrosis: looking for the right operation. Ann Thorac Surgery 1997;64:975-8.

59. Doolabh N, Horswell S, Williams M, Huber L, Prince S, et al. Thoracoscopic sympathectomy for hyperhidrosis: indications and results. Ann Thorac Surg 2004;77:410-4; discussion 414.

60. Licht PB, Pilegaard HK. Gustatory side effects after thoracoscopic sympathectomy. Ann Thorac surg 2006;81:1043-7.

61. Licht PB, Jorgensen OD, Ladegaard L, Pilegaard HK. Thoracoscopic sympathectomy for axillary hyperhydrsis: The influence of T4. Ann Thorac Surg 2005;80:455-60.

62. Kwong KF, Cooper LB, Bennett LA, Burrows W, Gamliel Z, et al. Clinical experience in 397 consecutive thoracoscopic sympathectomies. Ann Thorac Surg 2005;80:1063-6; discussion 1066.

63. Baumgartner FJ, Toh Y. Severe hyperhydrosis: clinical features and current thoracoscopic surgical management. Ann Thorac surg 2003; $76: 1878-83$.

64. Lee DY, Kim DH, Paik HC. Selective division of T3 rami communicantes (T3 craniotomy) in the treatment of palmar hyperhydrosis. Ann thoarac Surg 2004;78:1052-5.

65. Furlan AD, Mailis A, Papagapiou M. Are we paying a high price for surgical mpathectomy? A systematic literature review of late complications. J Pain 2000;1:245-57.

66. Lin TS, Wang NP, Huang LC. Pitfalls and complication avoidance associated with transthoracic endoscopes sympathectomy for primary hyperhidrosis (analysis of 2200 cases). Int J Surg Invest 2001;2:377-85.

67. Lee DY, Kim DH, Paik HC. Selective division of T3 rami comunicantes (T3 ramicotorny) in the treatment of palmar hyperhidrosis. Ann Thorac Surg 2004;78:1052-5.

68. Coveliers H, Meyer M, Gharagozloo F, Wisselink W, Rauwerda J, et al. Robotic selective postganglionic thoracic sympathectomy for the treatment of hyperhidrosis. Ann Thorac Surg 2013;95:269-74.

69. Coveliers H, Meyer M, Gharagozloo F, Wisselink W. Selective sympathectomy for hyperhidrosis: technique of robotic transthoracic 
selective postganglionic efferent sympathectomy. Eur J Cardiothorac Surg 2013;43:428-30.

70. Gharagozloo F. Robotic selective thoracic sympathectomy for hyperhidrosis. Mini-invasive Surg 2020;4:14.

71. Gharagozloo F. Pain management following robotic thoracic surgery. Mini-invasive Surg 2020;4:8.

72. Nishimura JM, Goodwin M, Kneuertz P, Susan Moffatt-Bruce S, Merritt RE, et al. Robotic lobectomy costs and quqlity of life. Miniinavsive Surg 2020;4:11.

73. Kneuertz PJ, Singer E, D’Souza DM, Mahmoud Abdel-Rasoul M, Moffatt-Bruce SD, et al. Hospital cost and clinical effectiveness of robotic-assisted versus video-assisted thoracoscopic and open lobectomy: a propensity score-weighted comparison. J Thorac Cardiovasc Surg 2019;157:2018-26. 